\title{
Genetic parameters for growth traits in South African Brahman cattle
}

\author{
B.A. Pico ${ }^{\#}$, F.W.C. Neser and J.B. van Wyk \\ Department of Animal, Wildlife and Grassland Sciences, University of the Free State, P.O. Box 339, Bloemfontein 9300, \\ South Africa
}

\begin{abstract}
Genetic parameters for growth traits in the South African Brahman breed were estimated using ASREML from data records of birth weight $(\mathrm{BWT})=41509$, weaning weight $(\mathrm{WWT})=37$ 705, yearling weight $(\mathrm{YWT})=$ 22682 and final weight $($ FWT $)=13055$ collected between 1985 and 2002. The direct additive contribution to BWT, WWT, YWT and FWT were $0.28,0.14,0.14$ and 0.18 respectively. The corresponding maternal heritability estimates were $0.11,0.06,0.05$ and 0.03 respectively. The maternal permanent environmental component due to the dam contributed $3-7 \%$ of the total phenotypic variances of the traits under consideration. The corresponding contribution of herd-year-season $\mathrm{x}$ sire interaction ranges from $5 \%$ to $6 \%$. The genetic correlation between animal effects was -0.36 for BWT. The prospects of improvement of these traits by selection seem possible and contribution of maternal permanent environment due to dam is of considerable importance as maternal effects.
\end{abstract}

Keywords: Birth weight, Bos indicus, final weight, heritability, maternal effects, weaning weight, yearling weight

"Corresponding author. E-mail: 2001107420@student.uovs.ac.za

\section{Introduction}

The Brahman is a tropically adapted Bos indicus breed developed from cattle of Indian origin. It is one of the numerous cattle breeds in South Africa adapted to tropical and subtropical conditions. The main features of the Brahman breed are its ability to withstand extreme climates (adaptability) and it excels in crossbreeding programmes. Records on growth performance of the South African Brahman has been collected for many years, Mostert et al. (1998) evaluated some performance records of Brahman participating in the National Beef Cattle Improvement Scheme for the period of 1976 to 1996.

Considerable research efforts have been directed towards estimating genetic parameters for various growth traits in beef cattle. Review articles by Koots et al. (1994) and Lobo et al. (2000) describe many of the parameters estimates for several pre-weaning and post-weaning growth traits in different beef cattle breeds from different countries. Genetic parameters are unique to the population in which they are estimated and they may change over time due to selection and management decisions. Thus, this paper presents estimates of genetic parameters for growth traits of South African Brahman cattle under extensive grazing management systems.

\section{Materials and Methods}

Data utilised in this study were obtained from the South African Brahman Breeder's Society with 181509 pedigree records of animals born between 1955 and 2002. Records available for analyses within traits are summarised in Table 1. The age ranges for the different traits were: weaning weight (WWT) (80-300 days); yearling weight (YWT) (301-500 days) and final weight (FWT) (501-900 days). Seasons were formed using the distribution of records per month, comparison of means per month and testing of contrasts between months. Based on the outcome of this analysis, season of calving was classified as follows: January to July (1), and August to December (2). Contemporary groups were formed by grouping animals born in the same herd, year and season, with a minimum of five animals per contemporary group. Only sires with five calves and herds with at least 10 records were used for analysis.

In order to determine the fixed effects to be included in the model, preliminary analyses were performed using PROC GLM (SAS, 1999). The fixed effects included in the analyses were age of the dam (3-12 years and older), contemporary groups defined as herd-year-season (varying between 500-1500), age of animal (covariate for WWT, YWT and FWT), sex (males and females) and management groups (varying between 9-20 classes). 
Peer-reviewed paper: Joint South African Society for Animal Science/Grassland Society of Southern Africa Congress

Variance components were estimated using the ASREML program (Gilmour et al., 1999), fitting an animal model throughout and incorporating all pedigree information available. An additional random effect was added which comprises of the herd-year-season $\mathrm{x}$ sire interaction. Suitability of the model was considered when a significant $(\mathrm{P}<0.05)$ increase in log likelihood occurred when adding an additional random effect. For the analysis of the traits the following model was used:

$$
\mathrm{Y}=\mathrm{X} \beta+\mathrm{Z}_{1} \mathrm{a}+\mathrm{Z}_{2} \mathrm{~m}+\mathrm{Z}_{3} \mathrm{c}+\mathrm{Z}_{4} \mathrm{cxs}+\varepsilon\{\text { with } \operatorname{cov}(\mathrm{a}, \mathrm{m})=0\}
$$

where, $Y$ is the $N x 1$ vector of records, $X, Z_{1}, Z_{2}, Z_{3}$ and $Z_{4}$ are known incidence matrices that associate levels of $\beta, \mathrm{a}, \mathrm{m}, \mathrm{c}$ and $\mathrm{cxs}$ with $\mathrm{Y}, \beta$ denotes the unknown vector of fixed effects, $\mathrm{a}$ is the unknown vector of breeding values for direct genetic effects, $m$ is the unknown vector of breeding values for maternal genetic effects, $\mathrm{c}$ is the unknown vector of permanent environmental effects contributed by dams to their progeny records, cxs is the vector of additional random effects due to contemporary group by sire interaction and $\varepsilon$ is the vector of residual effects. However, for BWT the model included the covariance between animal effects but ignored dam permanent environmental (c) effects.

Table 1 Description of data used after editing

\begin{tabular}{lllllllll}
\hline Trait & Animals $(\mathrm{n})$ & Sire $(\mathrm{n})$ & Dam $(\mathrm{n})$ & Herds $(\mathrm{n})$ & HYS $(\mathrm{n})$ & MGRP $(\mathrm{n})$ & Mean weight $(\mathrm{kg})$ & c.v. \\
\hline BWT & 41509 & 1410 & 18798 & 131 & 1495 & 9 & $32.3 \pm 4.0$ & 10.28 \\
WWT & 37705 & 1252 & 15662 & 95 & 1201 & 20 & $212 \pm 37$ & 11.58 \\
YWT & 22682 & 871 & 10547 & 72 & 751 & 19 & $274 \pm 54$ & 11.77 \\
FWT & 13055 & 555 & 6771 & 48 & 508 & 15 & $361 \pm 62$ & 10.42 \\
\hline
\end{tabular}

$\mathrm{n} \rightarrow$ number, MGRP $\rightarrow$ management group, c.v. $\rightarrow$ coefficient of variation

\section{Results and Discussion}

Analysis of variance indicated that all traits were influenced $(\mathrm{P}<0.0001)$ by all fixed effects. Male calves were heavier than females in all cases. The coefficient of variation (CV) increased from BWT to YWT and then decreased for FWT. The observed means (Table 1) were similar for BWT and WWT and slightly higher for YWT as well FWT reported for the same breed (Mostert et al., 1998). The higher values obtained for YWT and FWT is contrary to Mostert et al. (1998). This could be due to the age range classification used in this study.

Table 2 (Co)variance components and genetic parameters for BWT, WWT, YWT and FWT

\begin{tabular}{|c|c|c|c|c|c|c|c|c|c|c|c|c|}
\hline \multirow[b]{2}{*}{ Trait } & \multicolumn{7}{|c|}{ Variance components } & \multicolumn{5}{|c|}{ Genetic parameters } \\
\hline & $\sigma_{a}^{2}$ & $\sigma_{\mathrm{m}}^{2}$ & $\sigma_{c}^{2}$ & $\sigma_{\mathrm{e}}^{2}$ & $\sigma_{\mathrm{cxs}}^{2}$ & $\sigma_{p}^{2}$ & $\sigma_{\mathrm{am}}^{2}$ & $\mathrm{r}_{\mathrm{am}}$ & $\mathrm{h}_{\mathrm{a}}^{2}$ & $\mathrm{~h}_{\mathrm{m}}^{2}$ & $\mathrm{c}^{2}$ & $\mathrm{cxs} / \sigma_{\mathrm{p}}^{2}$ \\
\hline BWT & 3.33 & 1.29 & & 7.46 & 0.57 & 11.93 & -0.75 & -0.36 & 0.28 & 0.11 & & 0.05 \\
\hline WWT & 84.85 & 35.65 & 39.92 & 422.95 & 35.34 & 618.60 & & & 0.14 & 0.06 & 0.07 & 0.06 \\
\hline YWT & 144.22 & 57.07 & 31.24 & 769.75 & 67.12 & 1069.00 & & & 0.14 & 0.05 & 0.03 & 0.06 \\
\hline FWT & 265.74 & 46.68 & 55.81 & 1006.96 & 80.46 & 1456.00 & & & 0.18 & 0.03 & 0.04 & 0.06 \\
\hline
\end{tabular}

Variances: $\sigma^{2} \mathrm{a}$ - direct additive; $\sigma_{\mathrm{m}}^{2}$ - maternal additive; $\sigma_{\mathrm{c}}^{2}$ - permanent environmental; $\sigma_{\mathrm{e}}^{2}$ - error; $\sigma_{c x s}^{2}$ - contemporary group by sire interaction; $\sigma_{\mathrm{p}}^{2}$ - phenotypic; $\sigma_{\mathrm{am}}$ - covariance between animal effects; $\mathrm{r}_{\mathrm{am}}$ - genetic correlation between animal effects. Ratios: $\mathrm{h}_{\mathrm{a}}^{2}$ - direct; $\mathrm{h}_{\mathrm{m}}^{2}$ - maternal, $\mathrm{c}^{2}$ - fraction of phenotypic variance due to permanent environmental effects, $\mathrm{cxs} / \sigma_{\mathrm{p}}^{2}$ - fraction of phenotypic variance due to contemporary group by sire interaction effects.

The results of (co)variance components and ratios are summarized in Table 2. The $\mathrm{h}^{2}$ a for BWT (0.28) was slightly higher than estimates of 0.24 reported for Boran cattle (Bos indicus) in Ethiopia (Haile-Mariam \& Kassa-Mersha, 1995), and 0.22 reported for Nellore cattle (Bos indicus) in Brazil (Eler et al., 1995). Koots et al. (1994), Meyer (1992) and Plasse et al. (2002) reported higher estimates of 0.31, 0.33 and 0.33 respectively, in several beef breeds, Bos taurus and Bos taurus crosses as well as Brahman cattle. For WWT, Eler et al. (1995) obtained a similar $\mathrm{h}^{2}$ a of 0.13 . In contrast, Plasse et al. (2002) reported a value of 0.07 for Brahman cattle in Venezuela, whereas Diop \& Van Vleck (1998) found a higher estimate of 0.20 for Gobra cattle (Bos indicus) in Senegal. The $\mathrm{h}_{\mathrm{m}}^{2}$ estimate for BWT was 0.11 , and it is slightly higher than estimates of 0.08 (Plasse et al., 2002) 
and 0.09 (Haile-Mariam \& Kassa-Mersha, 1995). Diop \& Van Vleck (1998) reported an estimate of 0.04 for $\mathrm{h}_{\mathrm{m}}^{2}$, which is lower than the estimate found in this study. The $\mathrm{h}_{\mathrm{m}}^{2}$ estimate for WWT $(0.06)$ is in agreement with estimates of respectively 0.05 and 0.06 reported for Gobra (Diop \& Van Vleck, 1998), and Boran cattle (HaileMariam \& Kassa-Mersha, 1995). The genetic correlation between direct and maternal genetic effects was -0.36 for BWT, and could indicate a genetic antagonism between genes, and should be considered in a selection strategy. Estimates reported by different authors were also negative, for instance, estimates of -0.37 for Brahman cattle (Plasse et al., 2002), -0.72 for Nellore cattle (Eler et al., 1995), -0.17 for Gobra cattle (Diop \& Van Vleck, 1998) and -0.55 for Boran cattle (Haile-Mariam \& Kassa-Mersha, 1995).

Estimates of $\mathrm{h}^{2}$ awere 0.14 and 0.18 for YWT and FWT. Respective estimates reported for YWT by Eler et al. (1995) and Haile-Mariam \& Kassa-Mersha (1995) amounted to 0.16 and 0.34. Diop \& Van Vleck (1998) reported estimates of 0.24 and 0.14 for YWT and FWT, whereas Plasse et al. (2002) reported an estimate of 0.13 for FWT. Maternal effects still exist for postweaning traits (Table 2). This was not expected, as animals are no longer dependent on their dams for milk. The $\mathrm{h}_{\mathrm{m}}^{2}$ for YWT were 0.10 (Eler et al., 1995), 0.048 (Haile-Mariam \& Kassa-Mersha, 1995) and 0.21 (Diop \& Van Vleck, 1998). The result of $\mathrm{h}_{\mathrm{m}}^{2}$ for FWT is similar to 0.03 reported for Australian Herefords (Meyer, 1992). However, higher estimates of 0.15 (Diop \& Van Vleck, 1998) and 0.08 (Plasse et al., 2002) were reported for $\mathrm{h}_{\mathrm{m}}^{2}$ in respect to Gobra and Brahman.

\section{Conclusion}

Direct heritability estimates indicate that selection can be effective in the population studied. The contribution of maternal and permanent maternal environment for WWT, YWT and FWT were small, indicating that these traits are more under direct gene control. Future research should centre on the relationship among growth traits of South African Brahman breed.

\section{References}

Diop, M. \& Van Vleck, L.D., 1998. Estimates of genetic parameters for growth traits of Gobra cattle. Anim. Sci. 66, 349-355.

Eler, J.P., Van Vleck, D.L., Ferraz, J.B.S \& Lobo, R.B., 1995. Estimation of variance due to direct and maternal effects for growth traits of Nellore cattle. J. Anim. Sci. 73, 3253-3258.

Gilmour, A.R., Cullus, B.R., Welham, S.J. \& Thompson, R., 1999. ASREML Reference manual. NSW, Agriculture Biometric No.3 NSW Department of Agriculture, Orange. 210 pp.

Haile-Mariam, M. \& Kassa-Mersha, H., 1995. Estimates of direct and maternal covariance components of growth traits in Boran cattle. J. Anim. Breed. Genet. 112, 43-52.

Koots, K.R., Gibson, J.P. \& Wilton, J.W., 1994. Analyses of published genetic parameter estimates for beef production traits. 1. Heritability. Anim. Breed. Abstr. 62, 309-388.

Lobo, R.N.B., Madalena, F.E. \& Viera, A.R., 2000. Average estimates of genetic parameters for beef and dairy cattle in the tropical regions. Anim. Breed. Abstr. 68, 433-462.

Meyer, K., 1992. Variance components due to direct and maternal effects for growth traits of Australian beef cattle. Lives. Prod. Sci. 31, 179-204.

Mostert, B.E., Groeneveld, E., Rust, T. \& Van der Westhuizen, J., 1998. Multitrait variance component estimation of South African beef breeds for growth traits. Proc $6^{\text {th }}$ World Congr. Gen. Appl. Livest. Prod. $23,145-152$.

Plasse, D., Verde, O., Fossi, H., Romero, R., Hoogesteijn, R., Bastidas, P. \& Bastardo, J., 2002. (Co) variance components, genetic parameters and annual trends for calf weights in a pedigree Brahman herd under selection for three decades. J. Anim. Breed. Genet. 119, 141-153.

SAS, 1999. Statistical Analysis Systems user's guide, Release 6.03. SAS Institute, Inc., Carey, NC, USA. 